\title{
Beneficial properties of lactic acid bacteria naturally present in dairy production
}

\author{
Monique Colombo ${ }^{1}$, Nathália P. A. Castilho², Svetoslav D. Todorov ${ }^{3}$ and Luís Augusto Nero ${ }^{1 *}$ (D)
}

\begin{abstract}
Background: Consumers are increasingly demanding for natural and beneficial foods, in order to improve their health and well-being. Probiotics play an important role in such demand, and dairy foods are commonly used as vehicles for such bacteria, represented predominantly by lactic acid bacteria. Due to consumers demand, food industry is constantly looking for novel bacterial strains, leading to studies that aims the isolation and characterization of their beneficial features. This study aimed to characterize the naturally occurring lactic acid bacteria obtained from a dairy environment, in order to assess their potential use as probiotics.

Results: Preliminary screening and PCR analysis, based on 165 rRNA sequencing, were applied to select and identify 15 LAB strains from the genera Lactobacillus $(n=11)$, Pediococcus $(n=2)$ and Weissella $(n=2)$. All strains showed resistance to low pH and the evaluated bile salt concentrations in vitro. The API ZYM test characterized the enzymatic activity of the strains, and a high $\beta$-galactosidase activity was observed in 13 strains. All strains presented resistance to simulated gastric $(3 \mathrm{~h})$ and intestinal $(4 \mathrm{~h})$ conditions in vitro, the ability to auto- and co-aggregate with indicator microorganisms and a high cell surface hydrophobicity. Most of the strains were positive for map and EFTu beneficial genes. All strains exhibited strong deconjugation of bile salts in vitro and all assimilated lactose.

Conclusions: The phenotypes exhibited in vitro and the presence of beneficial genes revealed the beneficial potential of the studied strains, demanding further analyses in a food matrix and in vivo to allow the development of a functional product, with health-related properties.
\end{abstract}

Keywords: Beneficial potential - lactic acid bacteria, Dairy

\section{Background}

Probiotics are defined as living organisms that benefit consumer health when ingested in adequate concentration by the World Gastroenterology Organization [1]. The rise in probiotic product consumption is fueled by the increasing trend in consumers seeking products that improve life quality. Health and well-being are directly linked to good nutrition, physical activity and lifestyle [2]. In this context, probiotic strains embrace the concept of good nutrition by assisting with health maintenance, through the prevention, control and treatment of diseases [3].

More research is needed to isolate and characterize beneficial bacteria with probiotic potential, to meet the consumer demand. Dairy production systems are

\footnotetext{
* Correspondence: nero@ufv.br

${ }^{1}$ Departamento de Veterinária, Universidade Federal de Viçosa. Campus UFV,

Viçosa, MG 36570-900, Brazil

Full list of author information is available at the end of the article
}

important sources of beneficial strains, and fermented products are still the main sources of probiotic bacteria [4]. Lactic acid bacteria (LAB) are one of the most significant groups of probiotic organisms, commonly used in fermented dairy products. Among other benefits, these microorganisms can enhance lactose digestion, stimulate the immune system, and prevent and treat diarrhea [5].

Thus, the current study aimed to explore the dairy production environment as a source of LAB strains with probiotic potential.

\section{Methods \\ Samples}

Raw milk, swabs from cow and goat saliva and vaginal mucosa, ruminal boluses, consumption water and silage were collected from dairy farms (goat and cattle) located in the Universidade Federal de Viçosa, Viçosa, Minas Gerais state, Brazil, with conventional management and 
production destined to dairy processing. The samples were obtained after agreement of the responsible sector for managing these farms (Animal Science Department, Universidade Federal de Viçosa) and kept refrigerated before the following analyses.

\section{LAB isolation and characterization}

All samples were ten-fold diluted with $0.85 \% \mathrm{NaCl}(w / v)$. Selected dilutions were pour-plated in Man, Rogosa and Sharpe agar (MRS, Oxoid Ltd., Basingstoke, England) and MRS supplemented with $10 \mathrm{mg} / \mathrm{L}$ vancomycin (Sigma-Aldrich, St. Louis, MO, USA) for LAB enumeration, according to $\mathrm{M}$ Colombo, AEZ Oliveira, AF Carvalho and LA Nero [6]. Representative colonies were selected (10\% of the observed count) and tested for Gram stain and catalase reaction. The preliminary LAB characterized isolates (Gram-positive and catalase-negative) were freeze-dried and stored at $-20^{\circ}$ C. Further microbiological analyses were conducted, as described in the sections below.

\section{Gastric $\mathrm{pH}$ resistance}

Bacterial cells were grown overnight and prepared for the gastric $\mathrm{pH}$ resistance test, according to AA Argyri, G Zoumpopoulou, KG Karatzas, E Tsakalidou, GE Nychas, EZ Panagou and CC Tassou [7]. Resistance, assessed in triplicate, was evaluated by viable colony counts on MRS agar after incubation at $37^{\circ} \mathrm{C}$ for 0 and $3 \mathrm{~h}$, reflecting the time spent by food in the stomach. The resistance to low $\mathrm{pH}$ was performed as described by SD Todorov, DN Furtado, SMI Saad, E Tome and BDGM Franco [8], with some modifications. The isolates were grown at $37^{\circ} \mathrm{C}$ in MRS broth adjusted to $\mathrm{pH} 2.0,2.5$ and 3.0 with $\mathrm{HCl}$ until the cell density reached $3 \times 10^{7} \mathrm{CFU} / \mathrm{mL}$. All tests were conducted in sterile flat-bottom 96-well microtiter plates (Thermo Scientific, Waltham, MA, USA). In order to compare the count with the absorbance reading, optical density (OD) measurements were recorded at 650 $\mathrm{nm}$ at zero time and after incubation at $37^{\circ} \mathrm{C}$ for $3 \mathrm{~h}$ (aerobic condition), using a microtiter plate reader (BioTek Instruments, Inc., Winooski, VT, USA). Cultures grown in MRS broth corrected to $\mathrm{pH} 7.2$, served as the control.

\section{Bile resistance}

After preparing the bacterial inoculum [7], the resistance to bile salts was assessed, based on SD Todorov, DN Furtado, SMI Saad, E Tome and BDGM Franco [8], with some modifications. The isolates were grown at $37^{\circ} \mathrm{C}$ in MRS broth containing 0.5 and $3 \%(w / v)$ bile salts (Sigma), using 96-well microtiter plates, as described above. The OD readings were recorded at zero time and after incubation at $37^{\circ} \mathrm{C}$ for $4 \mathrm{~h}$. Cultures grown in MRS broth without bile served as the control.

\section{Molecular identification}

DNA of 82 selected isolates was extracted using a ZR Fungal/Bacterial DNA kit (Zymo Research, Irvine, CA, USA), and the DNA concentrations determined using NanoDrop (Thermo Scientific). Repetitive-element PCR and gel electrophoresis were performed according to the protocol described by B Dal Bello, K Rantsiou, A Bellio, G Zeppa, R Ambrosoli, T Civera and L Cocolin [9], using the single primer $\mathrm{GTG}_{5}$ (Additional file 1: Table S1). The electrophorezed gels were stained with Gel Red (Biotium, Inc., Hayward, CA, USA) and the bands were visualized and documented using an ultraviolet transilluminator (LPIX, Loccus Biotecnologia, São Paulo, SP, Brazil). Further differentiation of the LAB strains was achieved by random amplification of polymorphic DNA, as detailed by SD Todorov, $\mathrm{M}$ Wachsman, $\mathrm{E}$ Tomé, $\mathrm{X}$ Dousset, MT Destro, LMT Dicks, BDG de Melo Franco, M Vaz-Velho and D Drider [10]. Taxonomic identification was confirmed by sequencing of PCR-amplified $16 \mathrm{~S}$ rRNA using the universal pair of primers $8 \mathrm{~F}$ and $1512 \mathrm{R}$ [11]. Sequencing of the amplicons was done at the Center for Human Genome Studies, Institute of Biomedical Sciences, University of São Paulo (São Paulo, SP, Brazil). Obtained sequences were compared to reference sequences in GenBank, using the basic local alignment search tool (BLAST).

\section{Detection of enzymatic activity}

The enzymatic activity of each of the selected isolates was established, according to the API ZYM Kit (bioMérieux, Marcy-l'Étoile, France) manufacturer's manual. The following enzymes were tested: alkaline phosphatase, esterase, esterase/lipase, lipase, leucine arylamidase, valine arylamidase, cysteine arylamidase, trypsin, $\alpha$-chymotrypsin, acid phosphatase, naphthol-AS-BI-phosphohydrolase, $\alpha$-galactosidase, $\beta$-galactosidase, $\beta$-glucuronidase, $\alpha$-glucosidase, $\beta$-glucosidase, $N$-acetyl- $\beta$-glucosaminidase, $\alpha$-mannosidase and $\alpha$-fucosidase.

\section{Resistance to simulated gastric and intestinal conditions}

The tolerance of the selected strains to gastric and intestinal conditions was evaluated through an in vitro model described by KMO Santos, ADS Vieira, FCA Buriti, JCF Nascimento, MES Melo, LM Bruno, MF Borges, CRC Rocha, ACS Lopes and BDGM Franco [12]. The assay was performed three times for each strain, and the enumeration was done in duplicate. The survival rate (SR) of strains after gastric and enteric simulation were calculated using the equation: SR (\%) $=[\log \mathrm{CFU} N / \log \mathrm{CFU}$ $\left.N_{o}\right] \times 100$ [13], where $N_{O}$ and $N$ are the populations before and after the assay, respectively. The mean counts of log populations were compared by analysis of variance (ANOVA) and Tukey's test $(p<0.05)$ using XLSTAT 2016.01.26192 (Addinsoft, New York, NY, USA). 


\section{Aggregation and co-aggregation properties}

Aggregation abilities of the 15 selected LAB were tested using the method proposed by SD Todorov, DN Furtado, SMI Saad, E Tome and BDGM Franco [8] and Y Zhang, L Zhang, M Du, H Yi, C Guo, Y Tuo, X Han, J Li, L Zhang and L Yang [14]. Auto-aggregation was determined using the following equation: \% auto-aggregation $=\left[\left(\mathrm{OD}_{0}-\mathrm{OD}_{60}\right) / \mathrm{OD}_{0}\right] \times 100 . \mathrm{OD}_{0}$ and $\mathrm{OD}_{60}$ refer to the initial OD and the OD determined at $60 \mathrm{~min}$, respectively.

For evaluation of co-aggregation, the 15 selected strains were grown in $10 \mathrm{~mL}$ of MRS and Listeria monocytogenes Scott A, Enterococcus faecalis ATCC 19443 and Lactobacillus sakei ATCC 15521 in brain heart infusion (Oxoid) and MRS (Oxoid), respectively, at $37^{\circ} \mathrm{C}$ [8]. Co-aggregation was calculated using the following equation: \% co-aggregation $=\left[\left(\mathrm{OD}_{0-} \mathrm{OD}_{60}\right) / \mathrm{OD}_{60}\right] \times 100$. $\mathrm{OD}_{0}$ refers to the initial $\mathrm{OD}$, taken immediately after the relevant strains were paired. $\mathrm{OD}_{60}$ refers to the $\mathrm{OD}$ of the supernatant at $60 \mathrm{~min}$. Experiments were conducted in triplicate on two separate occasions.

The bacterial adhesion to hydrocarbons was tested as described by RJ Doyle and M Rosenberg [15], using 15 selected LAB strains. The percentage hydrophobicity was calculated as follows: \% hydrophobicity $=\left[\left(\mathrm{OD}_{580}\right.\right.$ reading $1-\mathrm{OD}_{580}$ reading 2$) / \mathrm{OD}_{580}$ reading 1$] \times 100$. Experiments were conducted in triplicate.

Finally, DNA obtained from the selected strains was analyzed by PCR for the presence of genes (Additional file 1: Table S1) related to the adhesion characteristics. The target genes included EF2380, EF2662, prgB, EF1249 [16], map, mub and EFTu [17].

\section{Bile salt deconjugation}

The selected strains were evaluated by their ability in deconjugate bile salts, as described by KMO Santos, ADS Vieira, FCA Buriti, JCF Nascimento, MES Melo, LM Bruno, MF Borges, CRC Rocha, ACS Lopes and BDGM Franco [12], using sodium salts of taurocholic acid (TC), taurodeoxycholic acid (TDC), glycocholic acid (GC) and glycodeoxycholic acid (GDC) (all from SigmaAldrich), in two repetitions and in duplicate.

\section{$\beta$-Galactosidase activity}

The assay described by KMO Santos, ADS Vieira, FCA Buriti, JCF Nascimento, MES Melo, LM Bruno, MF Borges, CRC Rocha, ACS Lopes and BDGM Franco [12] was considered to assess the $\beta$-galactosidase activity of the selected strains, using sterile filter paper discs impregnated with $o$-nitrophenyl- $\beta$-D-galactopyranose (ONPG discs, Fluka, Buchs, Switzerland), in two repetitions and in duplicate.

\section{Lactose assimilation}

The ability of LAB strains to metabolize lactose was tested by the strains cultivation in modified MRS, with $2 \%$ lactose as the single carbon source, at $37^{\circ} \mathrm{C}$ for $24 \mathrm{~h}$. Cultures obtained under the same conditions but on MRS with $2 \%$ glucose as the carbon source were used as the controls. The growth of the strains was estimated by viable cell counts, after plating 10 -fold serial dilutions on MRS agar medium [18]. The mean counts of log populations were compared by ANOVA $(p<0.05)$ using XLSTAT 2016.01.26192 (Addinsoft).

\section{Results}

\section{Screening}

A panel of 500 isolates was obtained from dairy environment samples, selected due to the results from the initial survival tests on $\mathrm{pH}$ and bile, being 394 both Gram-positive and catalase-negative. The final stage before conducting the proper assays for beneficial activity was survival in extreme conditions within the gastrointestinal tract (GIT); results were considered positive for growth in MRS broth at low $\mathrm{pH}$ and a high concentration of bile salts. After these screening tests, from 394 isolates, 82 were able to resist $\mathrm{pH} 2.0$ and $3 \%$ bile (in MRS broth) and were selected and molecularly fingerprinted. Results showed that from the 82 tested strains, 15 could be considered unique, so were chosen for taxonomical identification by sequencing of the PCR-amplified 16S rRNA. Lactobacillus casei MSI1, L. casei MSI5, L. acidophilus MVA3, L. harbinensis MSI3, L. plantarum MLE5, L. plantarum MSI2 and Pediococcus acidilactici MSI7 were isolated using MRS, and L. casei MRUV1, L. casei MRUV6, L. nagelli MSIV4, L. harbinensis MSIV2, L. fermentum SIVGL1, P. pentosaceus MLEV8, Weissella paramesenteroides MRUV3 and W. paramesenteroides MSAV5 were isolated using MRS-V.

Resistance to gastric $\mathrm{pH}$ and high bile concentrations are key features for cultures to be able to resist the unfavorable conditions of the GIT. As shown in Figs. 1 and 2, the 15 selected LAB strains had a high SR under the treatment conditions. Figure 1 illustrates that the tested strains were able to survive the gastric $\mathrm{pH}$. None of the studied cultures presented a population decrease higher than $1 \log$. This behavior was also reflected in the OD changes (Fig. 1). L. casei MSI5, L. casei MRUV6, L. acidophilus MVA3, L. harbinensis MSI3, L. harbinensis MSIV2, L. fermentum SIVGL1, L. plantarum MSI2, $P$. acidilactici MSI7 and W. paramesenteroides MSAV5 cultures displayed higher SRs compared to the other strains. Bile salts, at various concentrations, affected the survival of the tested strains. Among the 15 LAB strains selected for their good resistance to low $\mathrm{pH}$, all strains exhibited reasonably good bile tolerance after incubation 


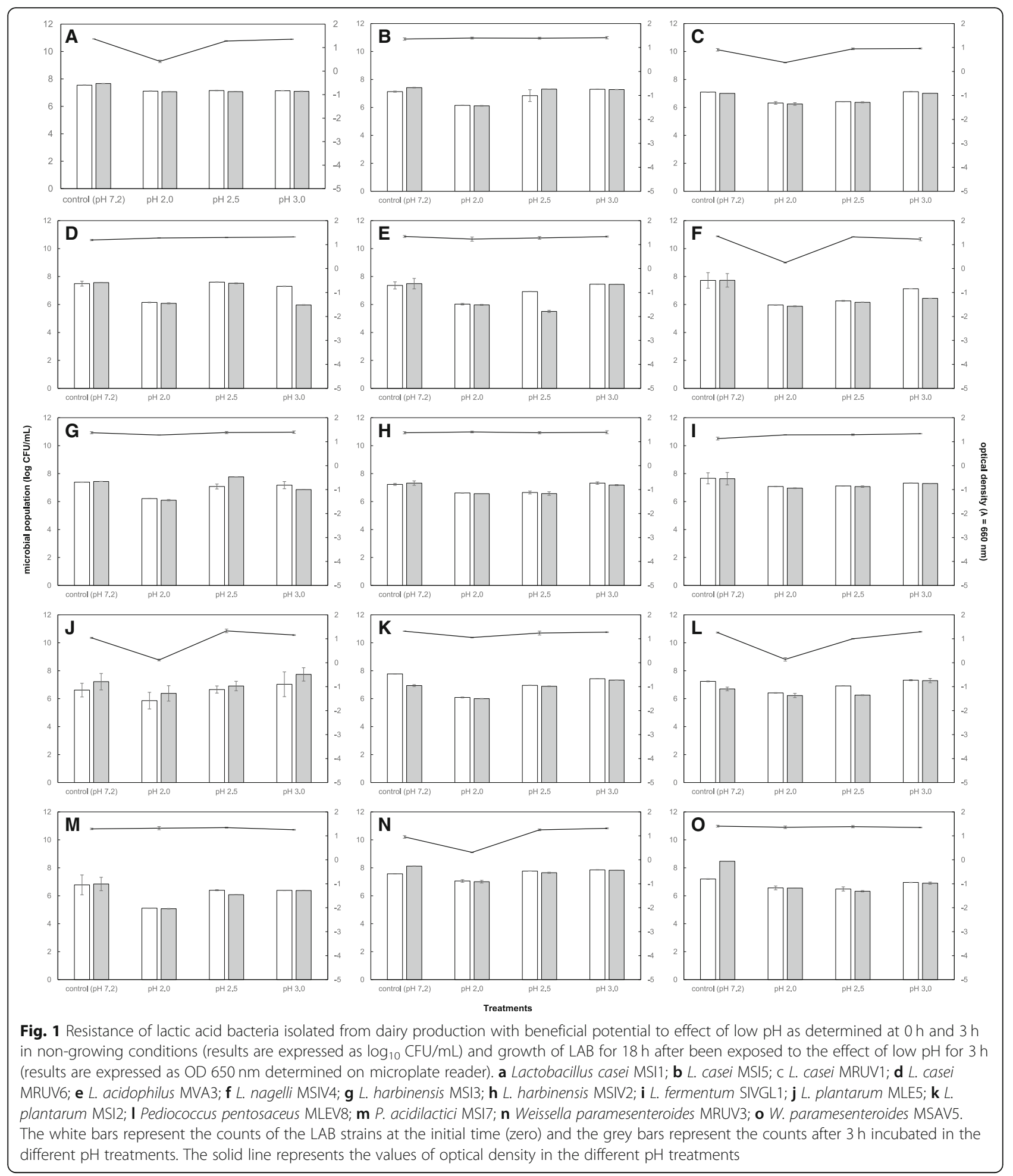

in the presence of bile salts for $4 \mathrm{~h}$ (Fig. 2). The changes in OD supported the findings (Fig. 2). The strains that exhibited a higher sensitivity to treatment with bile salts were $L$. casei MSI1, L. casei MRUV1, L. acidophilus MVA3 and W. paramesenteroides MSAV5.
The API ZYM kit test results for the enzymatic activity patterns of the assessed strains are presented in Table 1. All tested strains were positive for leucine arylamidase, acid phosphatase and naphthol-AS-BI-phosphohydrolase. L. harbinensis MSIV2 were positive for production of 17 


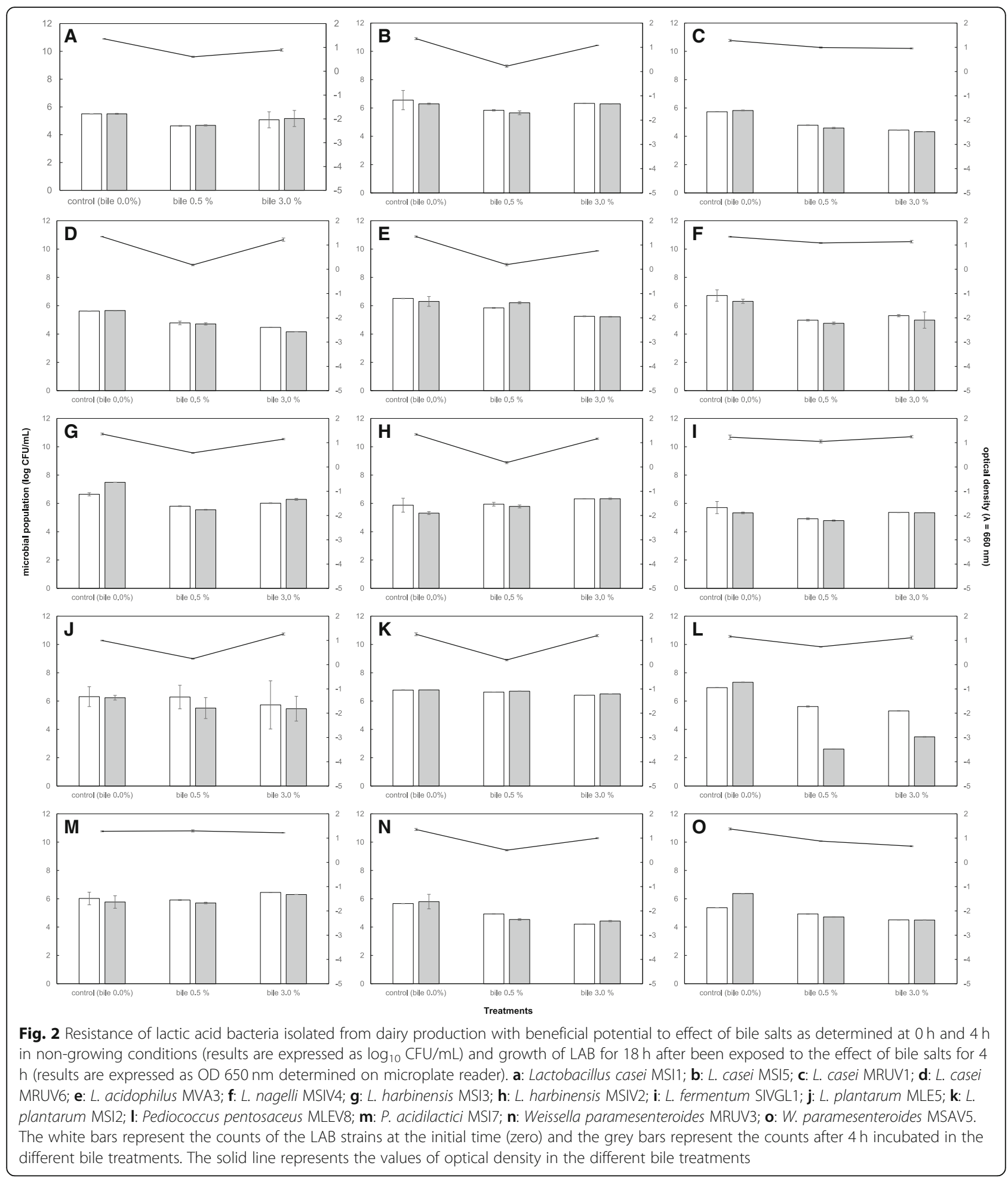

enzymes, as part of the API ZYM kit, and negative for $\alpha$-mannosidase and $\alpha$-fucosidase. Lipase, trypsin and $\beta$-glucuronidase activities were absent in most of the strains, and $\alpha$-mannosidase and $\alpha$-fucosidase activities were missing in all 15 tested strains.

\section{Beneficial properties in vitro}

Examination of the survival during in vitro simulation of the gastric and intestinal phases revealed the tested strains were able to survive and even multiply under the gastric phase conditions, reaching SR values above 91\% 


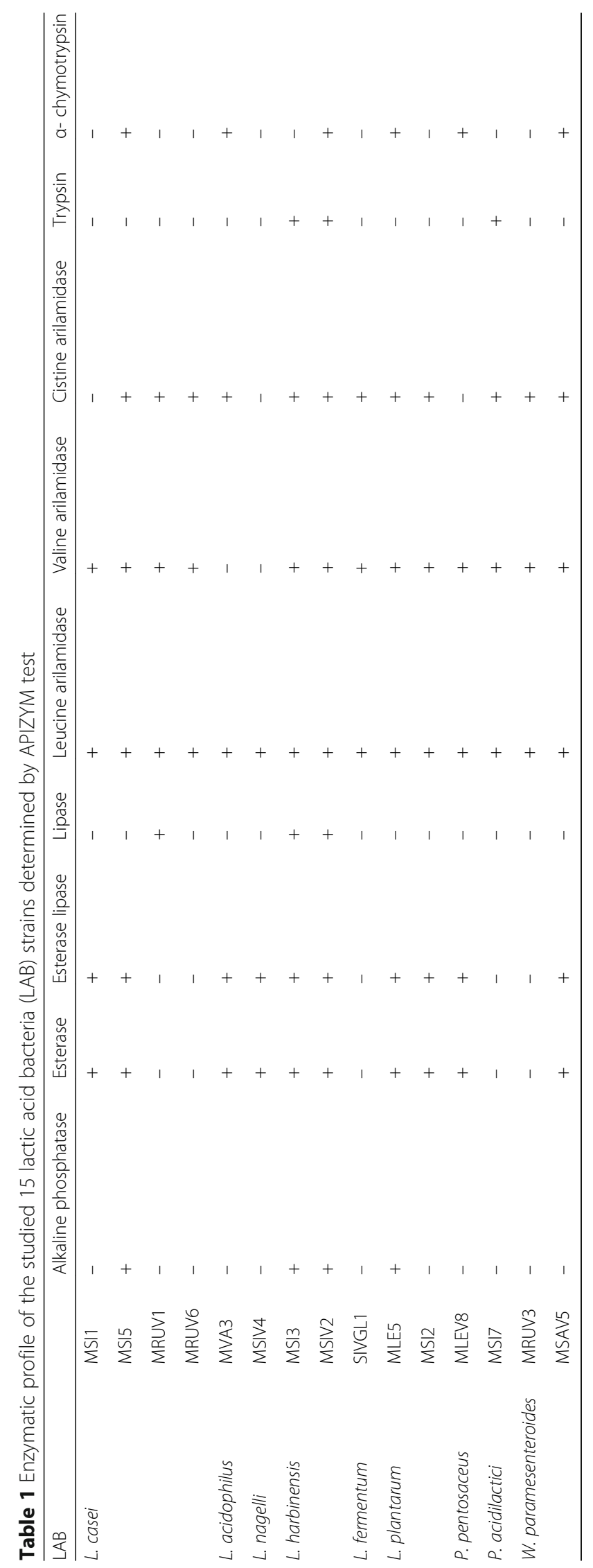


Colombo et al. BMC Microbiology

(2018) 18:219

Page 7 of 12

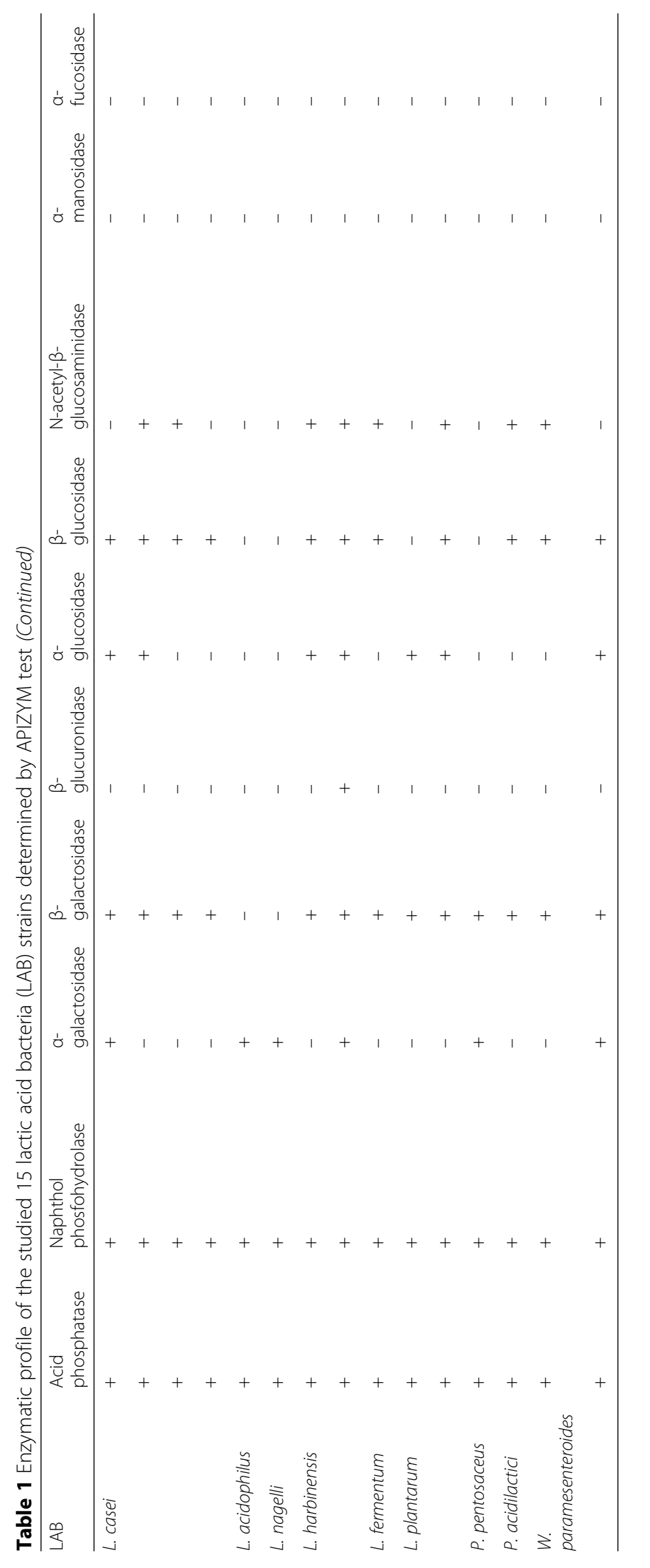


(Table 2). In the simulated intestinal phase environment, most cultures decreased their populations, reaching values between 46 and $102 \%$. However, all of the tested LAB cultures were able to survive the simulated upper GIT stages.

As already mentioned in this study, in addition to surviving the gastrointestinal host environment, probiotic bacteria must adhere to the GIT, if beneficial properties are related to the colonization of the host by probiotic LAB. The auto-aggregation ability allows bacteria to persist in the intestinal mucosa and, thus, promote their beneficial effects to the host. LAB co-aggregation is also considered a positive attribute, considering these same strains can manifest effects against pathogens. The autoand co-aggregation results (Table 3) appeared to be strain-specific.

Cell surface hydrophobicity is the ability of bacteria to present interactions with mucosal cells. Differences in the cell surface hydrophobicity result from the variation in the level of expression of cell surface proteins among strains of a species and are also due to environmental conditions, which affect the expression of surface proteins. All tested strains showed a high hydrophobicity (96-100\%, Table 3).

The identified genes linked to beneficial potential in the tested strains are summarized in Table 3 . The genes EF1249, EF2380 and $\operatorname{prgB}$ were not detected in any of the tested isolates, while EFTu was evident in 13 strains, map in 9 strains, EF2662 in 6 strains and mub in 4 strains.
All 15 investigated LAB strains recorded a high ability to grow on MRS agar plates containing $0.5 \%(w / v)$ sodium salts of TC, TDC, GC and GDC (data not shown). On ONPG discs, strong $\beta$-galactosidase activity was seen for only five LAB strains, including $L$. casei MSI1, $L$. casei MRUV6, L. plantarum MLE5, L. fermentum SIVGL1 and L. nagelli MSIV4 (data not shown). Among them, L. nagelli MSIV4 was negative for the $\beta$-galactosidase activity in the API ZYM kit (as mentioned above). Nonetheless, 13 strains had strong $\beta$-galactosidase activity according to the API ZYM results. The API ZYM kit is more sensitive than other tests and, consequently, more cultures are positive in that assay than other methods that assess $\beta$-galactosidase activity.

\section{Discussion}

MRS-V medium has a good potential to be applied in the isolation of LAB with beneficial potential. The presence of vancomycin is important to inhibit several other bacteria in the screening process. M Colombo, AEZ Oliveira, AF Carvalho and LA Nero [6] previously applied this medium to isolate and select LAB from different origins. The intrinsic vancomycin resistance of some species is due to their specific cell wall characteristics. Thus, MRS-V becomes an option to select probiotic cultures that possess this feature [19]. We isolated eight LAB strains from silage (L. casei MSI1 and MSI5, L. nagelli MSIV4, L. harbinensis MSI3 and MSIV2, L. fermentum SIVGL1, L. plantarum MSI2 and P. acidilactici MSI7), three from cow rumen (L. casei MRUV1, L. casei

Table 2 Survival of selected 15 lactic acid bacteria ( $L A B)$ strains to in vitro gastrointestinal conditions (gastric and intestinal phases)

\begin{tabular}{|c|c|c|c|c|c|c|}
\hline \multirow[t]{2}{*}{$\mathrm{LAB}$} & \multirow[t]{2}{*}{ Identification } & \multicolumn{3}{|c|}{ Population (log CFU/mL)* } & \multicolumn{2}{|c|}{ Survival rate** (SR\%) } \\
\hline & & Control (Initial) & Gastric phase & Intestinal phase & Gastric phase & Intestinal phase \\
\hline \multirow[t]{4}{*}{ L. casei } & MSI1 & $6.54 \pm 0.00$ & $6.79 \pm 0.01$ & $5.76 \pm 1.40$ & 103.8 & 88.1 \\
\hline & MSI5 & $8.74 \pm 0.00$ & $8.79 \pm 0.00$ & $6.76 \pm 2.13$ & 100.6 & 77.4 \\
\hline & MRUV1 & $9.15 \pm 0.00^{\mathrm{a}}$ & $8.80 \pm 0.00^{\mathrm{a}}$ & $7.30 \pm 0.40^{b}$ & 96.3 & 79.8 \\
\hline & MRUV6 & $8.29 \pm 0.00^{c}$ & $8.79 \pm 0.01^{\mathrm{a}}$ & $8.41 \pm 0.02^{b}$ & 106.0 & 101.4 \\
\hline L. acidophilus & MVA3 & $7.71 \pm 0.00^{c}$ & $7.84 \pm 0.00^{b}$ & $8.00 \pm 0.01^{a}$ & 101.7 & 71.0 \\
\hline L. nagelli & MSIV4 & $8.95 \pm 0.00^{\mathrm{a}}$ & $8.71 \pm 0.01^{b}$ & $7.90 \pm 0.03^{c}$ & 97.3 & 88.3 \\
\hline \multirow[t]{2}{*}{ L. harbinensis } & MSI3 & $8.87 \pm 0.00^{\mathrm{a}}$ & $8.77 \pm 0.01^{\mathrm{a}}$ & $5.46 \pm 2.20^{\mathrm{b}}$ & 98.9 & 61.6 \\
\hline & MSIV2 & $7.98 \pm 0.00^{\mathrm{a}}$ & $7.84 \pm 0.00^{b}$ & $4.04 \pm 0.08^{c}$ & 98.2 & 50.6 \\
\hline L. fermentum & SIVGL1 & $8.53 \pm 0.00^{a}$ & $7.77 \pm 0.01^{b}$ & $4.17 \pm 0.06^{c}$ & 91.1 & 48.9 \\
\hline \multirow[t]{2}{*}{ L. plantarum } & MLE5 & $8.48 \pm 0.00^{\mathrm{a}}$ & $7.77 \pm 0.00^{a b}$ & $6.00 \pm 1.41^{\mathrm{b}}$ & 91.6 & 70.8 \\
\hline & MSI2 & $7.78 \pm 0.00^{b}$ & $8.78 \pm 0.00^{\mathrm{a}}$ & $3.98 \pm 0.09^{c}$ & 112.9 & 51.2 \\
\hline P. pentosaceus & MLEV8 & $8.26 \pm 0.00^{\mathrm{a}}$ & $7.84 \pm 0.00^{a b}$ & $7.31 \pm 0.56^{\mathrm{b}}$ & 94.9 & 88.5 \\
\hline P. acidilactici & MSI7 & $9.00 \pm 0.00^{\mathrm{a}}$ & $8.79 \pm 0.00^{b}$ & $4.20 \pm 0.08^{c}$ & 97.7 & 46.7 \\
\hline \multirow[t]{2}{*}{ W. paramesenteroides } & MRUV3 & $6.78 \pm 0.00^{b}$ & $6.79 \pm 0.00^{\mathrm{b}}$ & $7.98 \pm 0.03^{\mathrm{a}}$ & 100.1 & 117.7 \\
\hline & MSAV5 & $7.39 \pm 0.00$ & $6.79 \pm 0.01$ & $5.25 \pm 1.52$ & 91.9 & 70.8 \\
\hline
\end{tabular}

${ }^{*}$ Average values \pm standard deviations, three independent repetitions; values followed by different letters are significantly different by ANOVA and Tukey $(p<$ $0.05) ;{ }^{*} \mathrm{SR}(\%)=[\log \mathrm{CFU} N / \log \mathrm{CFU} N 0] \times 100$, where NO and N are the population values before and after the assay, respectively 


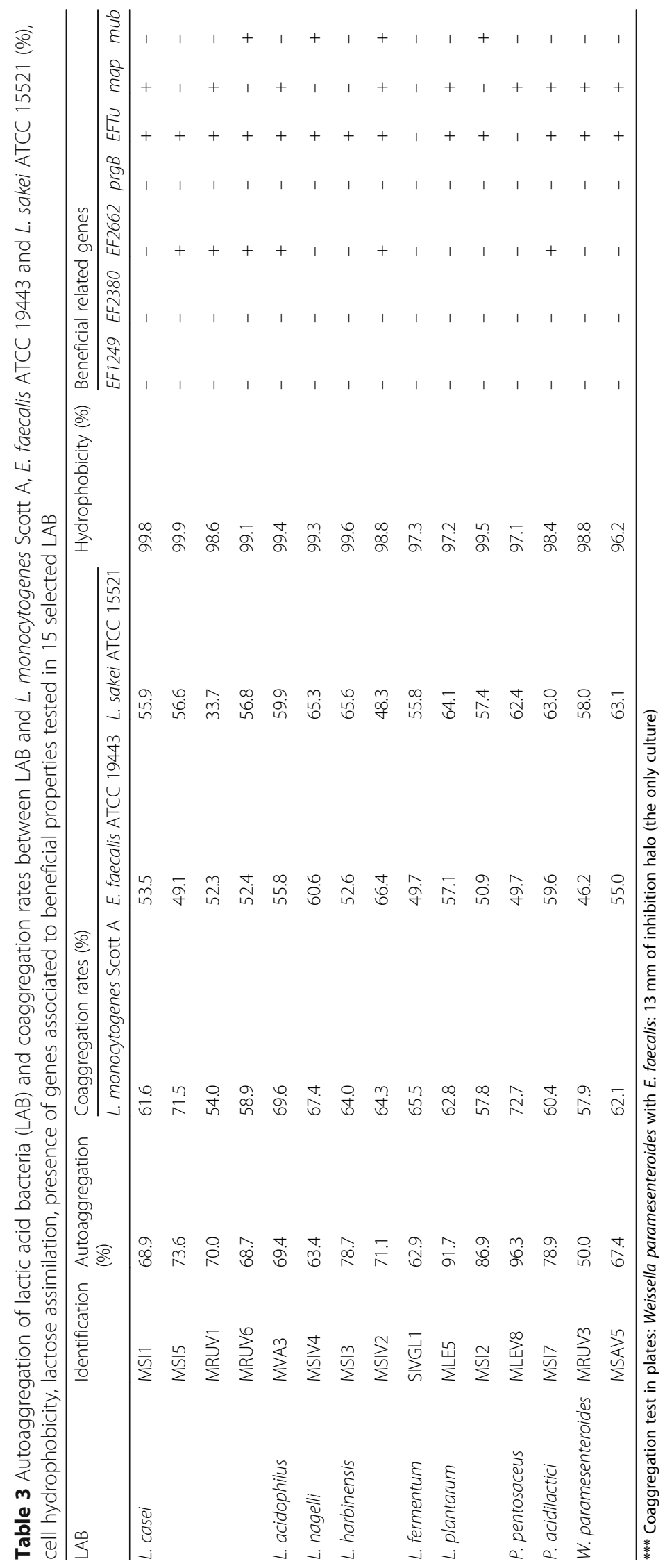


MRUV6 and W. paramesenteroides MRUV3), two from cow milk (L. plantarum MLE5 and $P$. pentosaceus MLEV8), one from cow vaginal mucosa (L. acidophilus MVA3) and one from cow oral mucosa (W. paramesenteroides MSAV5), respectively. Previous studies demonstrated the presence of $\mathrm{LAB}$ with probiotic potential in the dairy environment [20, 21]. From our knowledge, the current report is the first to isolate $L$. casei and $W$. paramesenteroides from cow rumen.

Although the in vitro results for resistance to low $\mathrm{pH}$ survival, this behavior is strain-specific (Fig. 1). These findings agreed with those of CG Vinderola and JA Reinheimer [22], regarding the greater tolerance of probiotic bacteria to low $\mathrm{pH}$ than other LAB. A García-Ruiz, D González de Llano, A Esteban-Fernández, T Requena, B Bartolomé and MV Moreno-Arribas [23] noted that Lactobacillus and Pediococcus strains were capable of surviving at low $\mathrm{pH}$ values. To the best of our knowledge, we are the first to investigate in vitro the $\mathrm{pH}$ and bile resistance of $W$. paramesenteroides. Moreover, all 15 tested LAB strains resisted the bile concentrations typically found in the intestine (Fig. 2), corroborating the findings of CG Vinderola and JA Reinheimer [22].

The enzymatic profiles of the Lactobacillus strains evaluated were, in general, similar to those reported by other authors $[24,25]$ The enzymatic activity is important for many functions of the tested cultures. For example, strains with high peptidase but with low proteinase and esterase/lipase activities may be useful in developing body and texture in cheese production and reducing bitterness [25]. $\beta$-Galactosidase activity, which is helpful in improving lactose tolerance in the gut, is pivotal for probiotic cultures [26]. Our results demonstrated the production of this enzyme for 13 of the 15 LAB strains. G Arora, BH Lee and M Lamoureux [27] compared the enzymatic profile of $20 \mathrm{~L}$. casei strains and indicated the presence of proteinase, peptidase and esterase/lipase activities. The potent peptidase and esterase activities in Lactobacilli have been highlighted by their roles in cheese production, like the acceleration of maturation and enzyme modification. Therefore, these results are valuable for both industrial and research purposes. N Tzanetakis and E Litopoulou-Tzanetaki [28] examined $P$. pentosaceus strains by the API ZYM system: leucine and valine aminopeptidase were found in all strains and $\beta$-galactosidase, esterase, esterase/lipase and acid phosphatase were detected in most of the strains, as noticed for $P$. pentosaceus MLEV8 (Table 1). However, $N$-acetyl- $\beta$-glucosaminidase, $\beta$-glucosidase, lipase and cysteine were negative for this strain, unlike the observations of $\mathrm{N}$ Tzanetakis and $\mathrm{E}$ Litopoulou-Tzanetaki [28]. To the best of our knowledge, we are the first to report the findings of the API ZYM system on $W$. paramesenteroides. Thus, the API
ZYM system helped identify and select the 15 LAB strains with beneficial potential.

The results for the tested isolates for the simulated intestinal phase (Table 2) were in agreement with previous studies with LAB. MB Pisano, S Viale, S Conti, ME Fadda, M Deplano, MP Melis, M Deiana and S Cosentino [24] recorded SRs of more than 98\% for Lactobacillus strains, as observed also by C Caggia, M De Angelis, I Pitino, A Pino and CL Randazzo [29] and KMO Santos, ADS Vieira, FCA Buriti, JCF Nascimento, MES Melo, LM Bruno, MF Borges, CRC Rocha, ACS Lopes and BDGM Franco [12]. V Vidhyasagar and K Jeevaratnam [30] showed that Pediococcus strains could survive both the gastric and intestinal phases. We did not find results for $W$. paramesenteroides strains in the literature.

The auto- and co-aggregation results observed for the tested isolates (Table 3), was previously recorded for other strains with beneficial properties [8]. L. plantarum MLE5 and P. pentosaceus MLEV8 displayed the highest auto-aggregation properties, of 91.7 and $96.3 \%$, respectively. All 15 tested LAB strains demonstrated more than $50 \%$ auto-aggregation, and correspondingly, 14 had more than $60 \%$. Fifteen strains showed $50 \%$ co-aggregation with L. monocytogenes Scott A. Additionally, 11 strains exhibited more than $50 \%$ co-aggregation with $E$. faecalis ATCC 19443, while 4 strains presented between 40 and $50 \%$. Co-aggregation with L. sakei ATCC 15521, which is non-pathogenic, may play a key role in facilitating the presence of this species in the human GIT. L. casei MRUV1 did not show good co-aggregation results (33.7\%). The other 13 strains showed between 48 and $63 \%$. Thus, all 15 LAB strains showed co-aggregation abilities with the pathogens tested but the degree of co-aggregation varied, depending on the specific strain. Prior literature studies also established that Lactobacillus presented a wide range of auto-aggregation of 5-68\% [29] and $28.8-87.7 \%$ [12], and up to $60 \%$ co-aggregation with L. monocytogenes [12].

SD Todorov, DN Furtado, SMI Saad, E Tome and BDGM Franco [8] documented that Lactobacillus presented low levels of co-aggregation with pathogens (L. monocytogenes and E. faecalis) and high levels with $L$. sakei, respectively. KW Lee, JY Park, HD Sa, JH Jeong, DE Jin, HJ Heo and JH Kim [31] showed that Pediococcus strains possessed strong auto-aggregation phenotypes, ranging between 65 and $69 \%$. In the same study, Pediococcus had 24-29\% co-aggregation, and Lactobacillus presented 16-26\% co-aggregation with E. faecalis ATCC 29212 [31]. V Vidhyasagar and $\mathrm{K}$ Jeevaratnam [30] mentioned that a Pediococcus strain exhibited a maximum aggregation of $89 \%$, with clumping of the cells and that this strain effectively co-aggregated (81\%) with $L$. monocytogenes. M Anandharaj, B Sivasankari, R Santhanakaruppu, M 
Manimaran, RP Rani and S Sivakumar [32] reported that a Weissella strain showed a maximum auto-aggregation of $79 \%$ and a co-aggregation of $68 \%$ with Escherichia coli MTCC 1089.

Cell surface hydrophobicity is also an important beneficial feature presented by the tested strains (Table 3). A good hydrophobicity has already been mentioned for a Lactobacillus strain (70\%) [29], Pediococcus strains (5579\%) [30] and both Lactobacillus (43-79\%) and Pediococcus strains (51.3\%) [8]. Conversely, we did not find any relevant studies for $W$. paramesenteroides.

The presence of the main surface proteins genes can be associated with a high adhesion ability, competitive exclusion of pathogens and adhesion-dependent stimulation of the immune system by probiotic LAB strains [17]. The tested isolates presented a variable results pattern for the tested genes (Table 3). EF2662, map, mub and EFTu play a key role in the mechanistic action of probiotic cultures: EF2662 is a novel putative binding protein gene, and it is responsible for recognizing adhesive matrix molecules, facilitating adhesion [33]. map and $m u b$ are mucus adhesion genes that allow adhesion to GIT mucosal cells. EFTu is an adhesion-like factor gene that also aids in cell adhesion. Finally, map, mub and EFTu are up-regulated in the presence of mucus, in proportional to increasing mucus concentrations [17].

LAB that present bile deconjugation capacity are desired for use in probiotic products for human consumption because studies show it is associated with the reduction of serum cholesterol by these cultures [34]. The results for bile salts deconjugation of the tested isolates were similar to those obtained in other studies, who also recorded strong deconjugation efficiencies for Lactobacillus, Pediococcus and Weissella strains [12, 29, 32].

Production of the $\beta$-galactosidase enzyme enables the probiotic cultures to assimilate lactose and minimize lactose intolerance. All $15 \mathrm{LAB}$ strains could assimilate lactose. Besides, eight LAB strains, namely, L. casei MSI5, L. casei MRUV1, L. casei MRUV6, L. acidophilus MVA3, L. harbinensis MSIV2, P. pentosaceus MLEV8, W. paramesenteroides MRUV3 and W. paramesenteroides MSAV5 showed better assimilation of lactose than glucose. V Vidhyasagar and K Jeevaratnam [30] and KW Lee, JY Park, HD Sa, JH Jeong, DE Jin, HJ Heo and JH Kim [31] published similar results. The findings are valuable for the dairy industry because these cultures will be able to grow in a milk-based environment. Also, these bacteria can endow fermented products with sensorial properties.

The tests carried out in the present study are the basis to identify LAB cultures that potentially can be used to create new functional foods. However, additional requisites must be evaluated for application in a commercial formulation, including LAB safety aspects, their application in a product formulation as starter cultures (viability, multiplication/fermentation in the selected food matrix), the conferred sensorial attributes, consumers acceptability, and in vivo tests to detect survival rates in the gastrointestinal tract. All these steps need to be conducted using validated analytical methods, in order to develop a new functional food that can provide beneficial heath effect $[35,36]$.

\section{Conclusions}

There is no doubt that probiotics play a significant role in nutrition and human medicine. However, specific research, regarding isolation, characterization, safety and application of these microorganisms in food is still necessary, as are accurate studies on their mechanisms of action in promoting the desired benefits. We confirmed the dairy chain as a potential source of beneficial strains, since the obtained isolates possess promising beneficial characteristics. Therefore, further assays are demanded to access their safety aspects, behavior in food matrix, sensorial conferred attributes, and their survival/ colonization in the gastrointestinal tract using an in vivo model.

\section{Additional file}

Additional file 1: Table S1. PCR primers used for identification, fingerprinting by rep-PCR and detection of beneficial properties related genes in lactic acid bacteria isolates obtained from a dairy production environment in Brazil. (DOCX 16 kb)

\section{Acknowledgments}

Not applicable.

\section{Funding}

This study was financed in part by the Coordenação de Aperfeiçoamento de Pessoal de Nível Superior - Brasil (CAPES) - Finance Code 001, Conselho Nacional de Desenvolvimento Científico e Tecnológico (CNPq) and Fundação de Amparo à Pesquisa do Estado de Minas Gerais

(FAPEMIG). None of these agencies had any role in the design of the study, the collection, analysis, and interpretation of data and in writing this manuscript.

\section{Availability of data and materials}

All the data supporting our findings is contained within the manuscript. The obtained sequences of 165 rRNA region for strains identification and the detailed results obtained for each strain are available from the corresponding author on reasonable request.

\section{Authors' contributions}

MC planned, performed experiments, aided in data analysis, and prepared the manuscript. NPAC performed experiments, aided in data analysis, and prepared the manuscript. SDT designed experiments, aided in data analysis, and aided in preparing and editing the manuscript. LAN designed and performed experiments, aided in data analysis, and aided in preparing and editing the manuscript. All authors read and approved the final manuscript.

Ethics approval and consent to participate

Animal samples used in this study were obtained according the procedures approved by the Ethic Committee in Animal Use from Universidade Federal de Viçosa, Viçosa, MG, Brazil. 


\section{Consent for publication}

Not applicable.

\section{Competing interests}

The authors declare that they have no competing interests.

\section{Publisher's Note}

Springer Nature remains neutral with regard to jurisdictional claims in published maps and institutional affiliations.

\section{Author details}

'Departamento de Veterinária, Universidade Federal de Viçosa. Campus UFV, Viçosa, MG 36570-900, Brazil. ²Departamento de Veterinária, Campus UFV Universidade de São Paulo, Faculdade de Ciências Farmacêuticas, 36570-900, Viçosa, MG, Brazil. ${ }^{3}$ Departamento de Alimentos e Nutrição Experimental, Av. Prof. Lineu Prestes, 580, Bloco 1, Cidade Universitária, São Paulo, SP 05508-000, Brazil.

Received: 24 January 2018 Accepted: 27 November 2018

\section{Published online: 19 December 2018}

\section{References}

1. WGO. World gastroenterology organisation practice guideline: probiotics and prebiotics, vol. 10; 2009.

2. Ouwehand AC, Röytiö H. Probiotic fermented foods and health promotion: Elsevier; 2014

3. FAO/WHO: FAO/WHO Expert consultation on evaluation of health and nutritional properties of probiotics in food including powder milk with live lactic acid bacteria. In. Córdoba, Argentina; 2001: 1-4.

4. Karimi R, Mortazavian AM, Amiri-Rigi A. Selective enumeration of probiotic microorganisms in cheese. Food Microbiol. 2012;29(1):1-9.

5. Ashraf R, Shah NP. Immune system stimulation by probiotic microorganisms. Crit Rev Food Sci Nutr. 2014;54(7):938-56.

6. Colombo M, Oliveira AEZ, Carvalho AF, Nero LA. Development of an alternative culture medium for the selective enumeration of Lactobacillus casei in fermented milk. Food Microbiol. 2014;39:89-95.

7. Argyri AA, Zoumpopoulou G, Karatzas KG, Tsakalidou E, Nychas GE, Panagou EZ, Tassou CC. Selection of potential probiotic lactic acid bacteria from fermented olives by in vitro tests. Food Microbiol. 2013:33(2):282-91.

8. Todorov SD, Furtado DN, Saad SMI, Tome E, Franco BDGM. Potential beneficial properties of bacteriocin-producing lactic acid bacteria isolated from smoked salmon. J Appl Microbiol. 2011;110(4):971-86.

9. Dal Bello B, Rantsiou K, Bellio A, Zeppa G, Ambrosoli R, Civera T, Cocolin L. Microbial ecology of artisanal products from north west of Italy and antimicrobial activity of the autochthonous populations. LWT Food Sci Technol. 2010;43(7):1151-9.

10. Todorov SD, Wachsman M, Tomé E, Dousset X, Destro MT, Dicks LMT, de Melo Franco BDG, Vaz-Velho M, Drider D. Characterisation of an antiviral pediocin-like bacteriocin produced by Enterococcus faecium. Food Microbiol. 2010;27(7):869-79.

11. Felske A, Rheims H, Wolterink A, Stackebrandt E, Akkermans ADL. Ribosome analysis reveals prominent activity of an uncultured member of the class Actinobacteria in grassland soils. Microbiology. 1997;143(9):2983-9.

12. Santos KMO, Vieira ADS, Buriti FCA, Nascimento JCF, Melo MES, Bruno LM, Borges MF, Rocha CRC, Lopes ACS, Franco BDGM. Artisanal Coalho cheeses as source of beneficial Lactobacillus plantarum and Lactobacillus rhamnosus strains. Dairy Science \& Technology. 2015;95(2):209-30.

13. Wang AN, Yi XW, Yu HF, Dong B, Qiao SY. Free radical scavenging activity of Lactobacillus fermentum in vitro and its antioxidative effect on growingfinishing pigs. J Appl Microbiol. 2009;107(4):1140-8.

14. Zhang Y, Zhang L, Du M, Yi H, Guo C, Tuo Y, Han X, Li J, Zhang L, Yang L. Antimicrobial activity against Shigella sonnei and probiotic properties of wild lactobacilli from fermented food. Microbiol Res. 2011;167(1):27-31.

15. Doyle RJ, Rosenberg M. Measurement of microbial adhesion to hydrophobic substrata. Methods Enzymol. 1995;253:542.

16. Fortina MG, Ricci G, Borgo F, Manachini PL, Arends K, Schiwon K, Abajy MY, Grohmann E. A survey on biotechnological potential and safety of the novel Enterococcus species of dairy origin, E. italicus. Int J Food Microbiol. 2008;123(3):204-11.

17. Ramiah K, van Reenen CA, Dicks LMT. Expression of the mucus adhesion genes mub and mapA, adhesion-like factor EF-Tu and bacteriocin gene plaA of Lactobacillus plantarum 423, monitored with real-time PCR. Int J Food Microbiol. 2007:116(3):405-9.

18. Pelinescu D, Chifiriuc MC, Ditu LM, Sarbu I, Bleotu C, Vassu I, Stocia I, Lazar V, Corcionivoschi N, Sasarman E. Selection and characterization of the probiotic potential of some lactic acid bacteria isolated from infant feces. Romanian Biotechnological Letters. 2011;16(3):6178-89.

19. Nelson RRS. Intrinsically vancomycin-resistant gram-positive organisms: clinical relevance and implications for infection control. J Hosp Infect. 1999; 42(4):275-82

20. Otero MC, Morelli L, Nader-Macías ME. Probiotic properties of vaginal lactic acid bacteria to prevent metritis in cattle. Lett Appl Microbiol. 2006;43(1):91-7.

21. Banwo K, Sanni A, Tan H. Technological properties and probiotic potential of Enterococcus faecium strains isolated from cow milk. J Appl Microbiol. 2013;114(1):229-41.

22. Vinderola CG, Reinheimer JA. Lactic acid starter and probiotic bacteria: a comparative "in vitro" study of probiotic characteristics and biological barrier resistance. Food Res Int. 2003;36(9-10):895-904.

23. García-Ruiz A, González de Llano D, Esteban-Fernández A, Requena T, Bartolomé B, Moreno-Arribas MV. Assessment of probiotic properties in lactic acid bacteria isolated from wine. Food Microbiol. 2014;44:220-5.

24. Pisano MB, Viale S, Conti S, Fadda ME, Deplano M, Melis MP, Deiana M, Cosentino S. Preliminary evaluation of probiotic properties of Lactobacillus strains isolated from sardinian dairy products. Biomed Res Int. 2014;2014:9.

25. Georgieva R, Iliev I, Haertlé T, Chobert J, Ivanova I, Danova S. Technological properties of candidate probiotic Lactobacillus plantarum strains. Int Dairy J. 2009;19(11):696-702.

26. de Vrese M, Stegelmann A, Richter B, Fenselau S, Laue C, Schrezenmeir J: Probiotics - compensation for lactase insufficiency. Am J Clin Nutr 2001, 73(2 Suppl):421S-429S.

27. Arora G, Lee BH, Lamoureux M. Characterization of enzyme profiles of Lactobacillus casei species by a rapid API ZYM system. J Dairy Sci. 1990;73(2): 264-73

28. Tzanetakis N, Litopoulou-Tzanetaki E. Biochemical activities of Pediococcus pentosaceus isolates of dairy origin. J Dairy Sci. 1989;72(4):859-63.

29. Caggia C, De Angelis M, Pitino I, Pino A, Randazzo CL. Probiotic features of Lactobacillus strains isolated from Ragusano and pecorino Siciliano cheeses. Food Microbiol. 2015;50:109-17.

30. Vidhyasagar $V$, Jeevaratnam K. Evaluation of Pediococcus pentosaceus strains isolated from idly batter for probiotic properties in vitro. J Funct Foods. 2013;5(1):235-43.

31. Lee KW, Park JY, Sa HD, Jeong JH, Jin DE, Heo HJ, Kim JH. Probiotic properties of Pediococcus strains isolated from jeotgals, salted and fermented Korean sea-food. Anaerobe. 2014;28:199-206.

32. Anandharaj M, Sivasankari B, Santhanakaruppu R, Manimaran M, Rani RP, Sivakumar S. Determining the probiotic potential of cholesterol-reducing Lactobacillus and Weissella strains isolated from gherkins (fermented cucumber) and south Indian fermented koozh. Res Microbiol. 2015;166(5): 428-39.

33. Solheim M, Brekke MC, Snipen LG, Willems RJL, Nes IF, Brede DA. Comparative genomic analysis reveals significant enrichment of mobile genetic elements and genes encoding surface structure-proteins in hospital-associated clonal complex 2 Enterococcus faecalis. BMC Microbiol. 2011;11(1):3.

34. Begley M, Hill C, Gahan CGM. Bile salt hydrolase activity in probiotics. Appl Environ Microbiol. 2006;72(3):1729-38

35. Mohammadi R, Sohrabvandi S, Mohammad Mortazavian A. The starter culture characteristics of probiotic microorganisms in fermented milks. Engineering in Life Sciences. 2012;12(4):399-409.

36. Cruz AG, Cadena RS, Walter EHM, Mortazavian AM, Granato D, Faria JAF, Bolini HMA. Sensory analysis: relevance for prebiotic, probiotic, and synbiotic product development. Compr Rev Food Sci Food Saf. 2010;9(4): 358-73. 